\title{
Stronger growth-inhibitory effect of interferon (IFN)-B compared to IFN- $\alpha$ is mediated by IFN signaling pathway in hepatocellular carcinoma cells
}

\author{
BAZARRAGCHAA DAMDINSUREN $^{1}$, HIROAKI NAGANO ${ }^{1}$, HIROSHI WADA ${ }^{1}$, MOTOI KONDO $^{1}$, \\ HIDEO OTA $^{1}$, MASATO NAKAMURA ${ }^{1}$, TAKEHIRO NODA ${ }^{1}$, JAVZANDULAM NATSAG ${ }^{2}$, \\ HIROFUMI YAMAMOTO ${ }^{1}$, YUICHIRO DOKI ${ }^{1}$, KOJI UMESHITA ${ }^{1}$, KEIZO DONO $^{1}$, \\ SHOJI NAKAMORI ${ }^{1}$, MASATO SAKON $^{1}$ and MORITO MONDEN ${ }^{1}$
}

Departments of ${ }^{1}$ Surgery, and ${ }^{2}$ Radiology, Graduate School of Medicine, Osaka University, Osaka, Japan

Received June 29, 2006; Accepted August 22, 2006

\begin{abstract}
Interferon (IFN) is a promising drug for prevention and treatment of hepatocellular carcinoma (HCC) in combination with chemotherapeutic agents. We previously reported that the spectra of antiproliferative activity and synergistic effect of IFN- $\beta$ when combined with anticancer drugs are more potent than those of IFN- $\alpha$ in HCC cells. However, the mechanism of the diverse antitumor effects of the IFNs is not understood yet. We studied the expression of IFN $\alpha$ receptor 2 (IFNAR2), STATs, and IFN- $\alpha$, IFN-ß's growth-inhibitory effect, signal transduction and binding to IFNAR2 on three HCC cell lines and a tumor xenografted mouse model (12 animals/group). From the results, IFN- $\beta$ showed a significantly stronger growth-inhibitory effect than IFN- $\alpha$ on the HuH7 cell line (expressing low IFNAR2), however it was similarly high on PLC/PRF/5 and weak on HLE. In the nude mouse tumor xenograft model, IFN- $\beta$ injection significantly suppressed tumor volume relative to vehicle injection, while IFN- $\alpha$ showed weaker growth-inhibition. IFN signal transduction (phosphorylated-STAT1, 3) induced by IFN- $\beta$ was higher than that by IFN- $\alpha$ in $\mathrm{HuH} 7$ and tumor xenografts. Pretreatment of hepatoma cells with anti-IFNAR2 antibody blocked the IFN signaling, more for IFN- $\alpha$. IFN- $\alpha$ 's antiproliferative effect was reduced by the antibody in lower concentrations compared to that of IFN- $\beta$. Taken together, the HCC cells that express low IFNAR2 and are resistant to IFN- $\alpha$ were sensitive to the growth-inhibitory effect of IFN- $B$, which might be mediated
\end{abstract}

Correspondence to: Dr Hiroaki Nagano, Department of Surgery, Graduate School of Medicine, Osaka University, 2-2 Yamadaoka E2, Suita, Osaka 565-0871, Japan

E-mail: hnagano@surg2.med.osaka-u.ac.jp

Key words: interferon- $\alpha / \beta$, interferon $\alpha$ receptor, STAT, antitumor effect, hepatocellular carcinoma by stronger IFN signal transduction and distinct binding to IFNAR compared to IFN- $\alpha$.

\section{Introduction}

Hepatocellular carcinoma (HCC) is one of the most common malignancies worldwide, with an estimated more than half a million new cases each year; most of which occur in Asia and Africa (1). The majority of patients are diagnosed at inoperable advanced stages and/or have recurrence or metastasis after therapy, and their prognoses remain extremely poor (2). Recent clinical trials on advanced HCC suggest that combination chemotherapies, especially 5-fluorouracil (5-FU) with interferon (IFN)- $\alpha$ may be effective (3-7). The response rate of these therapies ranged from 14 to $73 \%$ of selected patients with advanced HCC, unfortunately the remaining patients did not respond to the therapy and died within a few months. Therefore, more effective therapeutic strategies as well as alternative combination therapies are desirable in this field.

The actions of type I IFNs, which include IFN- $\alpha$ and $-\beta$, are mediated by their interaction with a multisubunit cellsurface receptor, IFN $\alpha$ receptor (IFNAR) 1 and IFNAR2 (8). From the IFNARs, IFNAR2 long-form (IFNAR2c) is suggested to be important for binding and signal transduction $(9,10)$. After IFN binds to the receptors, IFNAR-associated tyrosine kinases (JAK) are activated, followed by phosphorylation of signal transducer and activator of transcription factor (STAT) 1, 2, and 3. Phosphorylated STATs (pSTAT) form hetero- or homo-dimers, and thus transfer into the nucleus leading to transcription of numerous IFN responsive genes that mediate antiviral, growth-inhibitory, apoptotic, anti-angiogenic and immunomodulatory responses (8).

The mechanisms of the antitumor effect of IFN- $\alpha$ and its combination with 5-FU against $\mathrm{HCC}$ have been studied previously. In in vitro studies, we showed that combination of IFN- $\alpha$ and 5-FU induces apoptosis through IFNAR2 and delays the progression of G1 to S-phase in an HCC cell line expressing IFNAR2 $(11,12)$. Moreover, the spectra of the antiproliferative activity and synergistic effect of IFN- $B$ when 
combined with anticancer drugs are more potent than those of IFN- $\alpha$ in HCC cells in vitro (13). However, the underlying mechanism of the diverse antitumor effect of IFN- $\alpha$ and IFN- $\beta$ is not understood yet. Therefore, the present study was conducted to confirm and to clarify the dissimilar antitumor effect of the IFNs in vitro and in vivo, concerning IFN signal transduction.

\section{Materials and methods}

Interferons and antibodies. Human purified natural IFN- $\alpha$ (OIF; Otsuka Pharmaceutical, Tokyo, Japan) and IFN-B (IFN, Mochida; Mochida Pharmaceutical, Tokyo, Japan) were used in this study. The specific activities were $2.12 \times 10^{8}$ international units $(\mathrm{IU}) / \mathrm{mg}$ and $3.7 \times 10^{8} \mathrm{IU} / \mathrm{mg}$, respectively, and were used in the calculation of IFN concentrations in $\mathrm{ng} / \mathrm{ml}$ for the experiments. Specific rabbit anti-human IFNAR2 (developed by Otsuka Pharmaceutical using recombinant human IFNAR2 as described in ref. 14), STAT1, pSTAT1 (Tyr701) (Cell Signaling Technology, Beverly, MA), STAT2, pSTAT2 (Tyr689) (Upstate Biotechnology, Lake Placid, NY), STAT3, pSTAT3 (Tyr705) (Cell Signaling Technology), actin (Sigma, St. Louis, MO), and donkey anti-rabbit coupled to horseradish peroxidase (Amersham Biosciences, Buckinghamshire, UK) antibodies were used.

Cell lines and culture. Human HCC cell lines, HuH7, PLC/ $\mathrm{PRF} / 5$ and HLE, were purchased from the Japanese Cancer Research Resources Bank (Tokyo). The cells were maintained in Dulbecco's modified Eagle's medium supplemented with $10 \%$ fetal bovine serum (FBS), $100 \mathrm{U} / \mathrm{ml}$ penicillin and $100 \mu \mathrm{g} / \mathrm{ml}$ streptomycin at $37^{\circ} \mathrm{C}$ in a humidified incubator with $5 \% \mathrm{CO}_{2}$ in air.

For the study of phosphorylated STAT proteins, the cells were cultured in a medium containing $0.5 \%$ FBS for 2 days and then in FBS-free medium for $2 \mathrm{~h}$. After that they were incubated in medium with or without a desired concentration of IFN- $\alpha$ or IFN- $\beta$ for selected time periods and harvested for Western blotting.

Growth inhibitory assay. Growth curves with IFNs were drawn as described previously (15). Briefly, the cells $\left(2 \times 10^{4}\right.$ cells/well for $\mathrm{HuH} 7,4 \times 10^{4}$ cells/well for PLC/PRF/5, $0.7 \times 10^{4}$ cells/well for HLE) were uniformly seeded in 12-well dishes, and from the next day they were treated with or without IFN- $\alpha$ or IFN- $\beta$ $(2.5 \mathrm{ng} / \mathrm{ml})$. On alternate days, the medium with IFNs was changed and the viable cells were counted using a Celltac semi-automatic analyzer (Nihon Kohden, Tokyo, Japan). The concentration of the IFNs applied here (equal to $500 \mathrm{IU} / \mathrm{ml}$ of IFN- $\alpha$ ) was based on that used in our previous studies $(11-13,16)$.

Nude mouse tumor xenograft model and IFN treatment. The $\mathrm{HuH} 7$ cells were injected subcutaneously $\left(5 \times 10^{6}\right.$ cells/animal $)$ into the left flank of 4-week-old BALB/c nu/nu female mice (Japan Clea, Tokyo, Japan). Tumor size was measured twice a week using a caliper and tumor volume was calculated using the formula [tumor volume $\left(\mathrm{mm}^{3}\right)=\left(\mathrm{a}^{2} \mathrm{x} \mathrm{b}\right) / 2$ ], where $\mathrm{a}$ is the width and $\mathrm{b}$ is the length in $\mathrm{mm}$. After attainment of tumor volume of $\sim 50 \mathrm{~mm}^{3}$ (10 days after injection), the mice were randomly assigned to one of three groups of 12 animals each, and IFN- $\alpha$, IFN- $\beta$ (both $2 \times 10^{4}$ IU/animal) or PBS was injected subcutaneously three times a week. On the $21 \mathrm{st}$ treatment day the mice were sacrificed, and the tumors were harvested and stored at $-80^{\circ} \mathrm{C}$ for further examination. The animal care was in accordance with the institutional guidelines, and the experiments were approved by the animal research committee of Osaka University.

Western blot analysis. The sub-confluent growing cells or tumor samples were washed with PBS (Sigma) and lysed in an ice-cold RIPA buffer with $1 \mathrm{mM}$ sodium orthovanadate (15). Total protein concentration was determined using the Bradford protein assay (Bio-Rad, Hercules, CA) and Western blot analysis was performed as described in our previous studies $(12,15)$. The antibodies were used at the following dilutions: 1:100 for detection of IFNAR2; 1:1000 for total-, phosphorylated-STAT1, 3 and actin; and 1:500 for STAT2. The expression of proteins was evaluated by measuring the optical densities of protein bands, using the National Institute of Health Image analysis software version 1.61 and the expression value was calculated relative to that of actin.

Neutralizing assays. For neutralizing assay of the antiproliferative effect of IFNs, the cells were seeded to a 96-well microplate and, on the following day, escalating dilutions of anti-IFNAR2 antibody (1:500000-1:500, decided from experiments of cytotoxicity) were applied and, soon after ( $30 \mathrm{~min}$ ), either IFN- $\alpha$ or IFN- $\beta$ (until final concentration of $2.5 \mathrm{ng} / \mathrm{ml}$ ) was added. The number of viable cells was measured $72 \mathrm{~h}$ later by MTT assay as described previously (13). The anti-IFNAR2 antibody does not cross-react with human IFN- $\alpha$ and IFN- $\beta$ by immunoblot (as described by the manufacturer).

To study the IFN signaling with anti-IFNAR2 antibody, the cells were cultured in medium $(0.5 \% \mathrm{FBS})$ with or without the antibody (dilution 1:5000), and $24 \mathrm{~h}$ later they were treated with either IFN- $\alpha$ or IFN- $\beta(2.5 \mathrm{ng} / \mathrm{ml})$ for $40 \mathrm{~min}$, and thereafter harvested and probed to Western blotting.

Statistical analysis. Statistical analysis was performed using the Prism 4 program (GraphPad Software, San Diego, CA). Data from in vitro assays are expressed as mean \pm SD from at least three independent experiments, and results from animal model experiments are shown as mean \pm SEM. The Dunnett, and unpaired t-tests were used for analyses.

\section{Results}

IFN- $\beta$ exhibits a stronger growth-inhibitory effect than IFN- $\alpha$ on $\mathrm{HuH7}$ cells in vitro and on nude mice tumor xenograft in vivo. To verify the growth-inhibitory effect of the IFNs in HCC cells, we drew the 8-day growth curves with or without $2.5 \mathrm{ng} / \mathrm{ml}$ of IFN- $\alpha$ or IFN- $\beta$. As shown in Fig. 1, the IFNs exhibited diverse growth-inhibitory effects on the liver cells, i.e., strong growth-inhibition was observed on PLC/PRF/5 while IFNs did not show any effect on HLE (only with significant effect on the 8th day with IFN- $\beta$ ). On the other hand, in the $\mathrm{HuH} 7$ cell line, IFN- $\beta$ significantly inhibited the cell growth while IFN- $\alpha$ did not; on the 8th day the growth 

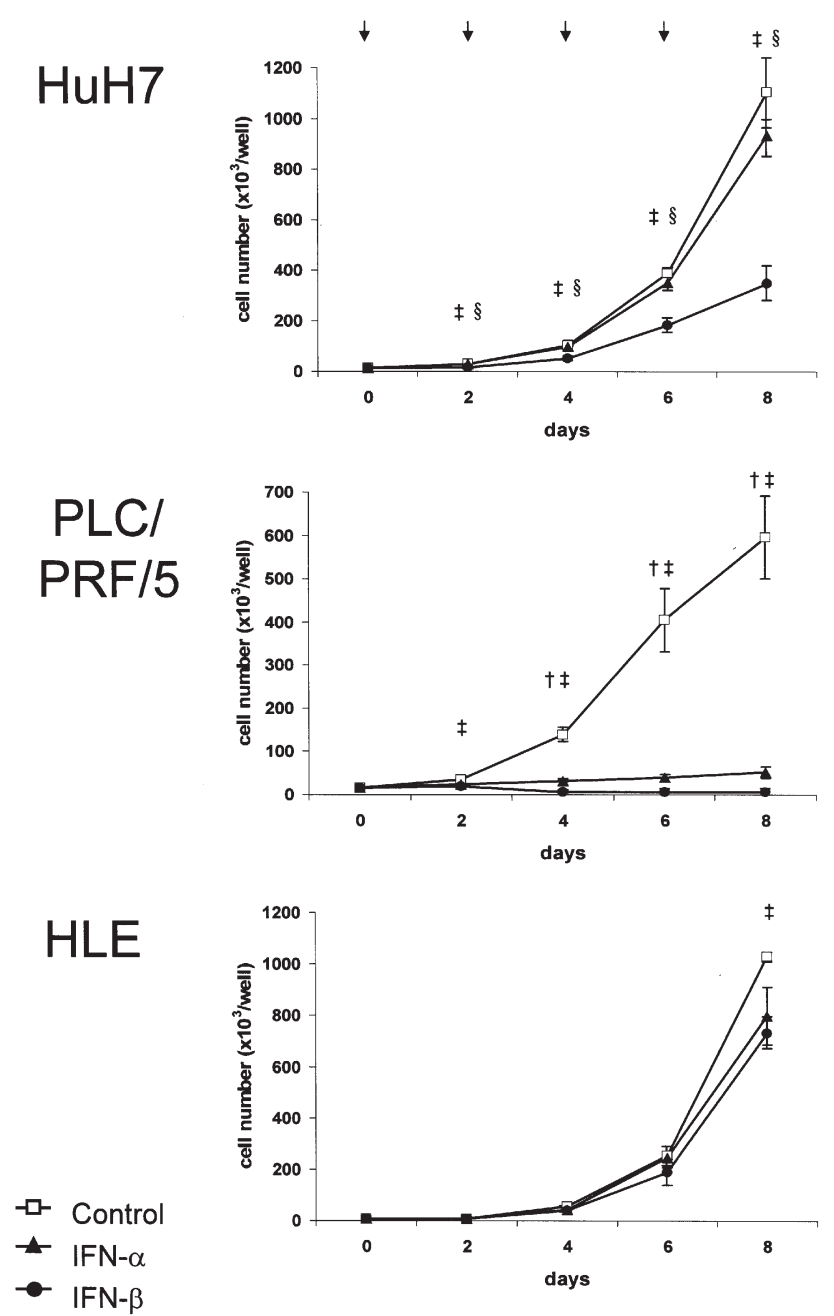

Figure 1. Growth-inhibitory effect of IFNs in HCC cell lines in vitro. Growth curves were drawn up to day 8 by counting viable cells treated or untreated with $2.5 \mathrm{ng} / \mathrm{ml}$ of IFN- $\alpha$ or IFN- $\beta$. Both IFNs exhibited strong cell growth suppression on the PLC/PRF/5 cell line. IFN- $\beta$ resulted in significant growth inhibition of $\mathrm{HuH} 7$ cells compared to the control and IFN- $\alpha$. HLE cells were resistant to both IFNs. Arrows denote change of fresh medium with the IFNs. ${ }^{\dagger} \mathrm{p}<0.05$, IFN- $\alpha$ vs vehicle; ${ }^{\dagger} \mathrm{p}<0.05$, IFN- $\beta$ vs control (both by Dunnett's tests); ${ }^{\S} \mathrm{p}<0.05$, IFN- $\alpha$ vs IFN- $\beta$ (by unpaired t-test).

was inhibited by $68.5 \%$ with IFN- $\beta$ ( $p<0.01$ vs control, by Dunnett's test) and $15.5 \%$ with IFN- $\alpha(\mathrm{p}>0.05)$. Moreover, the growth-inhibition was significantly stronger by IFN- $\beta$ than by IFN- $\alpha$ from the 2 nd day of treatment $(\mathrm{p}<0.05$, by unpaired t-test).

To examine the effect of IFNs in vivo, we studied the growth of $\mathrm{HuH7}$ tumor xenografts in nude mice with or without the IFN treatments $\left(2 \times 10^{4} \mathrm{IU} /\right.$ animal thrice a week). As shown in Fig. 2, IFN- $\beta$ therapy significantly inhibited tumor growth from the 10th day of treatment, compared with the vehicle ( $\mathrm{p}<0.05$ by unpaired t-test), while IFN- $\alpha$ treatment did not exhibit a significant growth-inhibitory effect (except on the 10 th day). On the 21 st post-treatment day, IFN- $\beta$ resulted in a $47 \%$ decline of the tumor volume compared to that in the control animals $(\mathrm{p}=0.03)$, however IFN- $\alpha$ caused only $19 \%$ tumor growth regression $(p>0.05)$. There was no difference in the body weights of animals in each group during the treatments (data not shown).

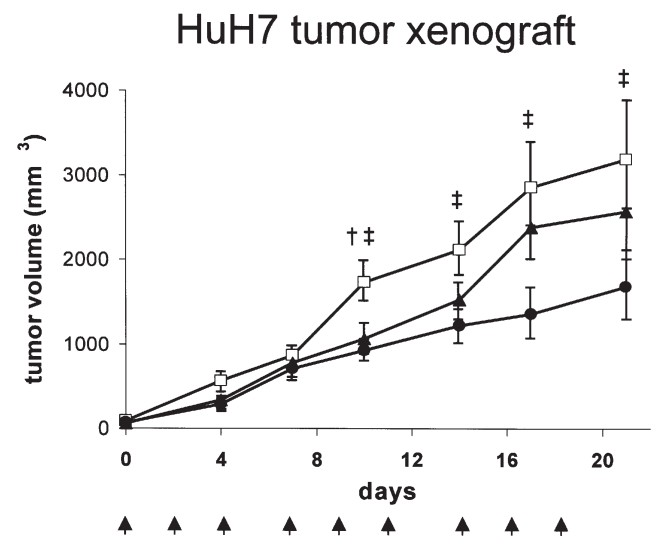

Figure 2. Effect of IFN- $\alpha$ and IFN- $\beta$ on tumor growth in vivo. IFN- $\beta$ therapy significantly inhibited the tumor growth from the 10th treatment day compared with the vehicle, while IFN- $\alpha$ exhibited less growth-inhibition (significant only on the 10th day). Arrows denote administration of the IFNs. ${ }^{\dagger} \mathrm{p}<0.05$, IFN- $\alpha$ vs vehicle; ${ }^{\ddagger} \mathrm{p}<0.05$, IFN- $\beta$ vs control (both by Dunnett's tests).

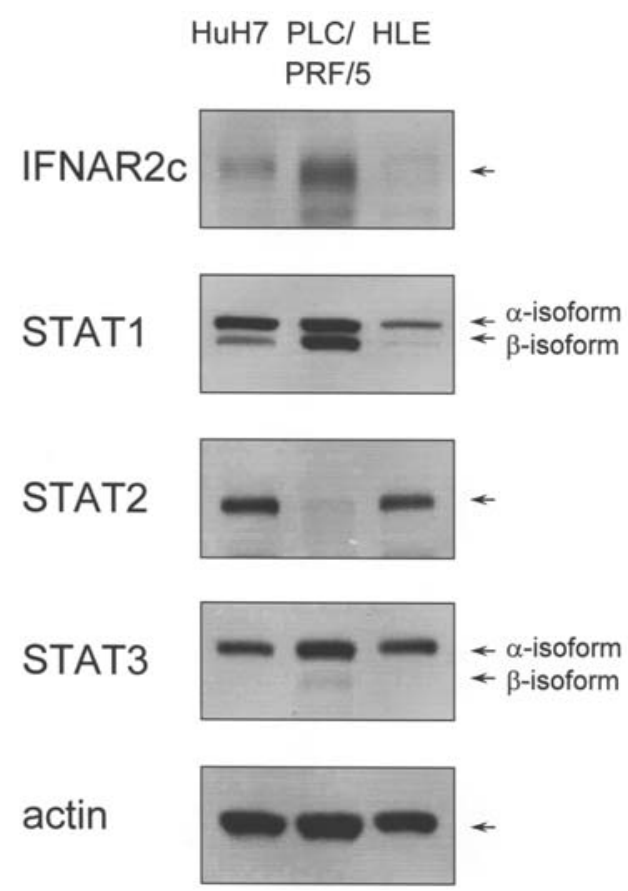

Figure 3. Expression of IFNAR2c and STATs in HCC cells. IFNAR2c was abundant in PLC/PRF/5, low in HuH7 and was lacking in HLE. STAT1 and 3 were expressed higher and STAT2 was less in PLC/PRF/5 compared to the other cells. Blots are representative of similar results of repeat experiments.

IFN- $\beta$-induced signaling is stronger than that of IFN- $\alpha$ in $\mathrm{HuH7}$ in vitro and in vivo. At first, we examined the expression of IFNAR2c and STAT proteins in the cell lines. As shown in Fig. 3, the expression of IFNAR2c was abundant in IFNsensitive PLC/PRF/5 cells, low in $\mathrm{HuH} 7$ and was lacking in HLE. STAT1 and 3 were expressed higher in PLC/PRF/5 than in other cells, however STAT2 was faint in PLC/PRF/5 while exhibiting clear bands in other cell lines.

To study IFN signal transduction, we treated the cells with different concentrations of the IFNs $(0,0.5,2.5,5.0 \mathrm{ng} / \mathrm{ml})$ for $20 \mathrm{~min}$ and assessed the expression and activation of STAT proteins. The phosphorylations of STAT1 and 3 were activated 
A IFN- None $\overbrace{\alpha \quad \beta} \overbrace{\alpha \beta}^{2.5} \overbrace{\alpha \quad \beta}^{5}$ STAT1

(p) $\rightarrow \quad----$

(t) $\rightarrow=-=-=$ STAT2

(p) $\rightarrow \quad n-m-m$

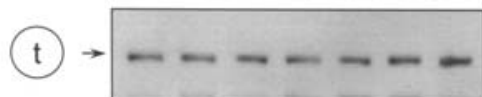

STAT3

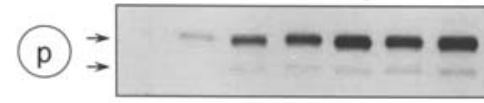

(t) $\rightarrow-\infty---$

actin

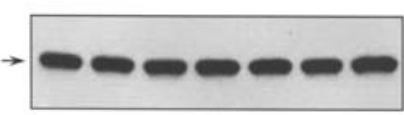

IFN- None $\overbrace{\alpha \quad \beta}^{0.5} \overbrace{\alpha \quad \beta}^{2.5} \overbrace{\alpha \quad \beta}^{5}$

STAT1

(p) $\rightarrow \square-$

(t) $\rightarrow=---$

STAT2

(p) $\rightarrow+2+\cdots$

(t) $\rightarrow--\cdots$

STAT3

(p) $\rightarrow$

(t) $\rightarrow-\infty-\infty=-$

actin

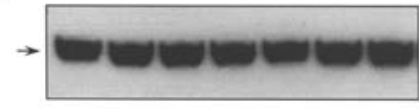

$\mathrm{HuH} 7$
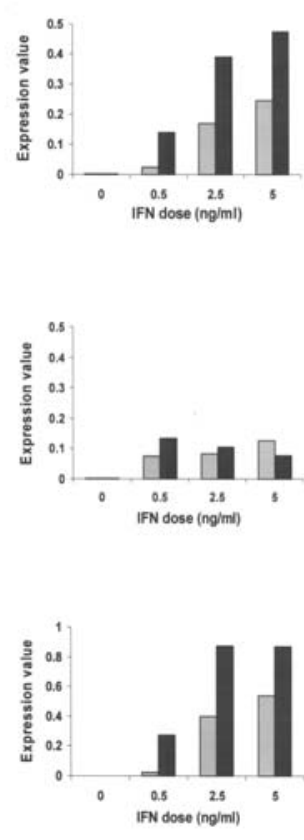

$\square$ IFN- $\alpha$

口IFN- $\beta$

HLE
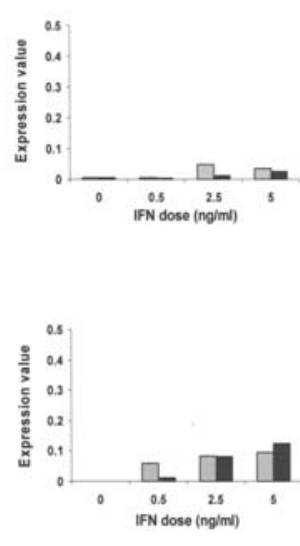

Time (min) $\overbrace{\alpha \beta}^{10} \overbrace{\alpha \beta}^{20} \overbrace{\alpha \beta}^{40} \overbrace{\alpha \beta}^{80}$

STAT1

(p) $\rightarrow \quad---\cdots$

(t) $\rightarrow=-=--=$

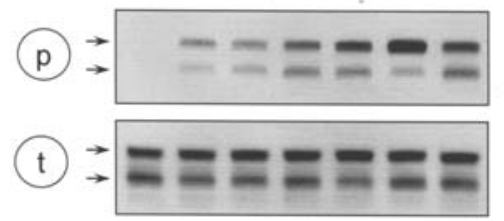

actin
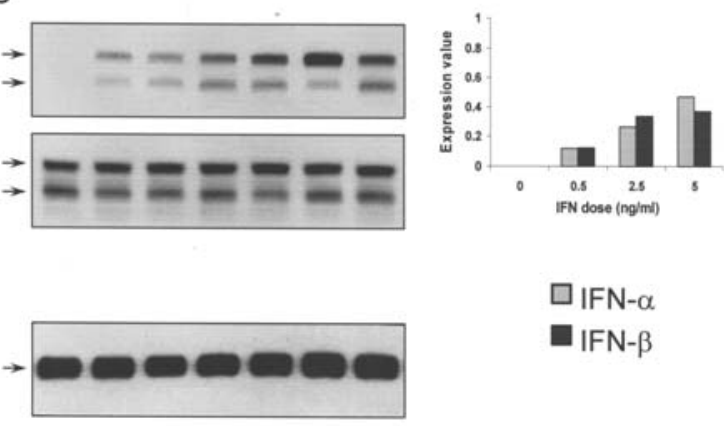

$\square$ IFN- $\alpha$

口IFN- $\beta$
$\mathrm{HuH} 7$
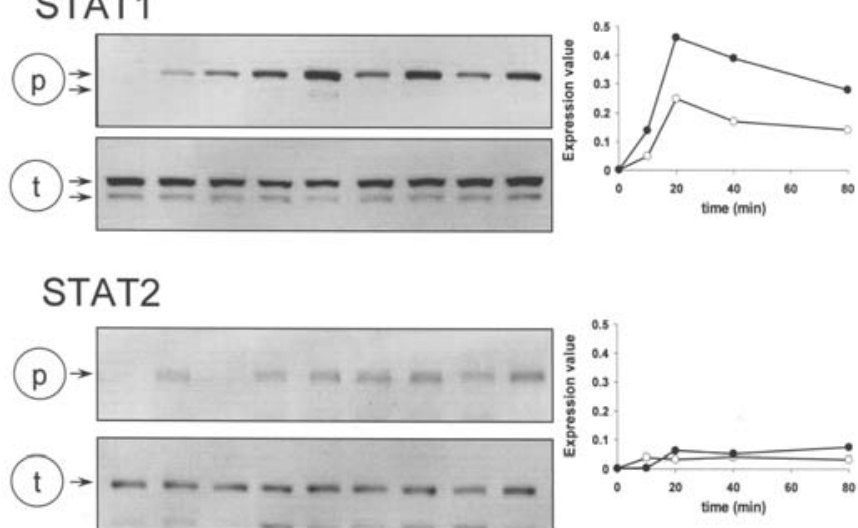

\section{STAT2}

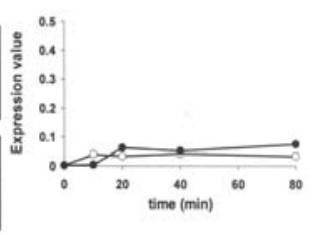

STAT3

(p) $\rightarrow \quad-\infty-\infty-\infty-\infty$

(t) $\rightarrow-\infty-\cdots-\infty$

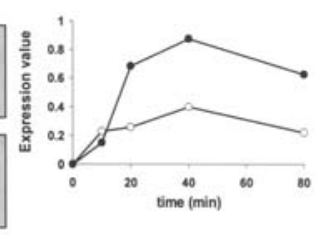

$\square$ IFN- $\alpha$

口IFN- $\beta$

actin

$-0-$ IFN- $\alpha$

- IFN- $\beta$ 
E IFN- None $\overbrace{\alpha \quad \beta}^{10} \overbrace{\alpha \beta}^{20} \overbrace{\alpha \quad \beta}^{40} \overbrace{\alpha \quad \beta}^{80}$

STAT1

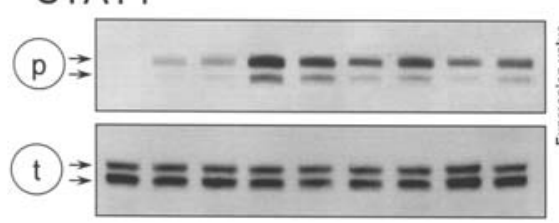

STAT2
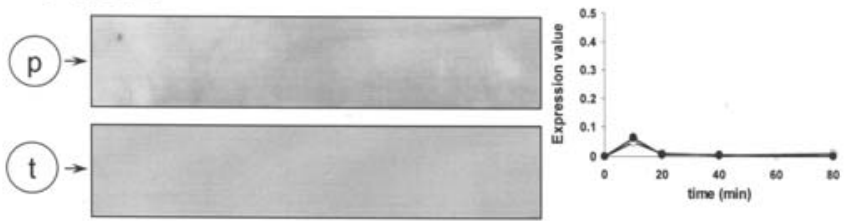

STAT3

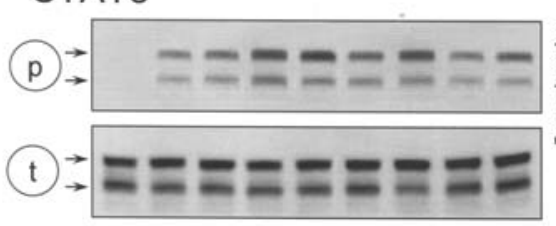

actin

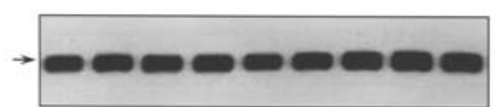

\section{$\mathrm{PLC} / \mathrm{PRF} / 5$}

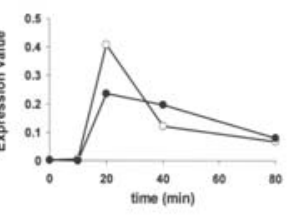

F

Time (min) $10 \quad 20 \quad 40 \quad 80 \quad$ HLE

IFN- None $\begin{array}{lllllllll}\alpha & \beta & \alpha & \beta & \alpha & \beta & \alpha & \beta\end{array}$

STAT1
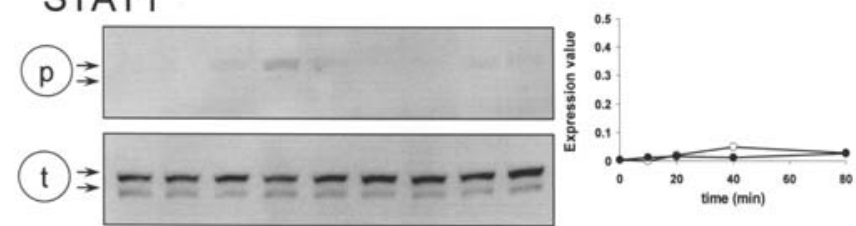

STAT2
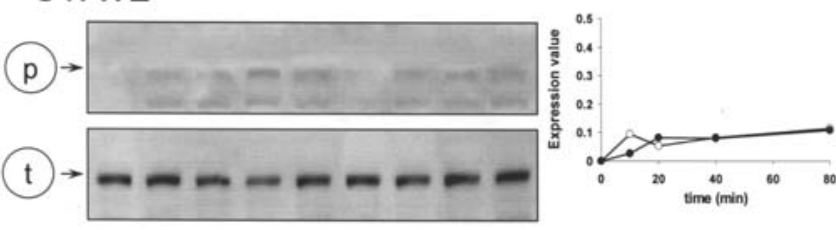

STAT3
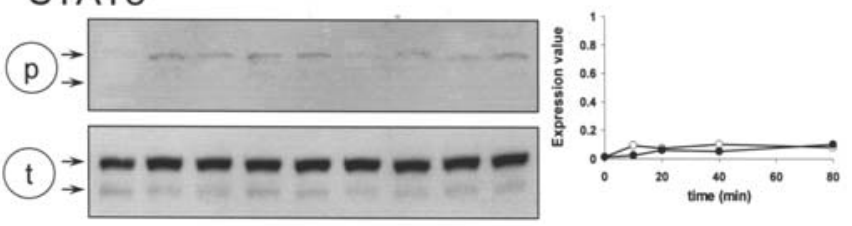

actin

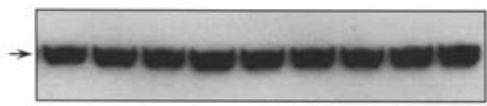

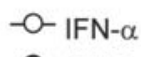

- IFN- $\beta$

Figure 4. Activation of STATs by the IFNs in HCC cells. (A-C) Dose-dependency of induction of STATs. The cells were incubated with medium alone or diverse doses of the IFNs for equal amounts of time. The phosphorylation of STAT 1 and 3 was dose-dependent from IFN concentration, and greater by IFN- $\beta$ induction than by IFN- $\alpha$ in HuH7 cells. However, pSTAT2 (A) and all total STATs were analogous. The signal transduction (pSTAT1, 3) induced by both IFNs was similarly intensive in PLC/PRF/5 (B) or faint in HLE cells (C). (D-F) Dynamics of STAT activation. The cells were treated for different amounts of time by either of the IFNs. In HuH7 cells, activation of STAT1 and 3 was noted for a longer time and at a higher level with IFN- $\beta$ than with IFN- $\alpha$ (D). p, phosphorylated; and t, total STAT. Graphs exhibit densities of respective pSTAT bands to actin. Data are representative of similar results of repeat experiments.

in a dose-dependent manner, while no such dose-dependent induction was observed for pSTAT2 (Fig. 4A-C). In the $\mathrm{HuH7}$ cell line, which is more responsive to the growthinhibitory effect of IFN- $\beta$ but not to that of IFN- $\alpha$ (Fig. 1), the phosphorylation of STAT1 and 3 was greater by IFN- $\beta$ than by IFN- $\alpha$, respectively 5.8-, 2.3-, 1.9-fold and 10.6-, 2.2-, 1.6-fold higher in each IFN dose (Fig. 4A). The signal transduction induced by the IFNs was similarly high in PLC/ PRF/5 (except expressing low pSTAT2), whereas it was equally faint in HLE cells (Fig. 4B and C).

When we examined the dynamics of STAT phosphorylation, the activation of STAT1 and 3 reached peaks within 20-40 min (Fig. 4D-F). In HuH7 cells, the higher pSTAT1 and 3 continued for a longer time with IFN- $\beta$ than with IFN- $\alpha$ (Fig. 4D). The expression of total STATs was not changed by the IFNs (corresponding lower blots).

Furthermore we examined the expression and activation of STATs in tumor xenograft samples. The IFN-B-treated tumors showed greater induction of pSTAT3 than IFN- $\alpha$ treated samples, while total STAT3 was analogous (Fig. 5). The activation of STAT1 and 2 was similarly faint in samples from both IFN-treated animals (data not shown).
Anti-IFNAR2 antibody suppresses differently the signaling and antiproliferative effects of IFN- $\alpha$ and IFN- $\beta$. Because the signal transductions induced by the IFNs were different, and IFNAR2c is responsible for IFN signaling $(9,10)$, we examined the IFN binding to the receptor using neutralizing antibody to the extracellular part of IFNAR2 on PLC/PRF/5 cells, which express abundant IFNAR2c (Fig. 2). Pretreatment of the cells with the antibody (dilution 1:5000) for $24 \mathrm{~h}$ blocked IFN signal transduction (pSTAT1) of both IFNs (Fig. 6A). The activation of STAT1 by IFN- $\alpha$ and $-\beta$ was decreased by 82.3 and $70.7 \%$ respectively. The expression of basic STAT1 did not change with addition of the antibody (data not shown).

When we examined the alteration of IFNs' anti-proliferative effect by anti-IFNAR2 antibody, it significantly reduced the effects in PLC/PRF/5 cells (Fig. 6B, asterisks denote significant differences compared to the IFN controls without the antibody by Dunnett's test). Furthermore, higher concentrations of the antibody were needed to suppress the effect of IFN- $\beta$ than of IFN- $\alpha$ (respectively dilutions 1:500 vs 1:5000). The effect of IFN- $\alpha$ disappeared with 1:5000 and 1:500 dilutions of the antibody ( $p>0.05$ vs without IFN by Dunnett's test), while 
A

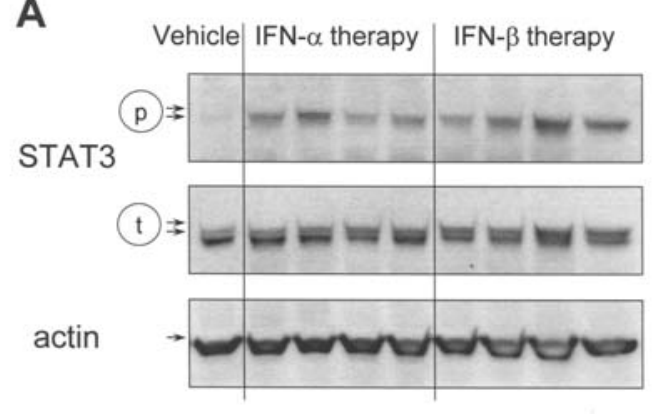

B
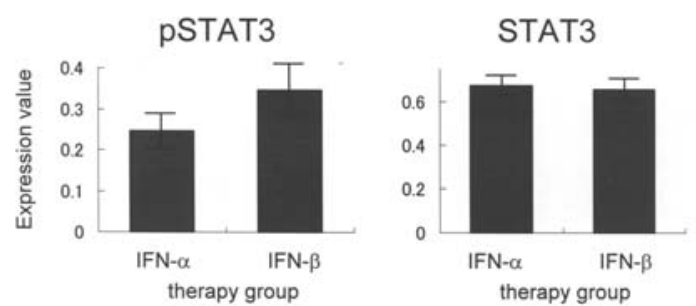

Figure 5. Expression and activation of STAT3 with the IFN treatments in tumor xenografts. One vehicle sample and four representative samples from each IFN-treated group are probed to Western blotting (A). IFN-B-treated tumors showed greater induction of STAT3 phosphorylation than IFN- $\alpha$ treated tumors, while total STAT3 was analogous (B). p, phosphorylated; and t, total STAT.

IFN- $\beta$ 's effect was still observed with the same dilutions $(\mathrm{p}<0.05$ vs without IFN).

\section{Discussion}

Herein we examined the growth-inhibitory action of IFN- $\alpha$ and IFN- $\beta$ on three HCC cell lines of different origin; PLC/ $\mathrm{PRF} / 5$ cells were very sensitive and HLE cells were resistant to both IFNs. On the other hand, $\mathrm{HuH7}$ cells, which showed resistance to the growth-inhibitory effect of IFN- $\alpha$, were sensitive to IFN-B (Fig. 1). IFN-B also exhibited a stronger antitumor effect in vivo on xenografted $\mathrm{HuH} 7$ tumor model nude mice (Fig. 2). Consistently, the previous studies reported that IFN- $\beta$ has greater antitumor effects than IFN- $\alpha$ on melanoma, squamous carcinoma and breast cancer cells (17-19), however the mechanism of such distinct effects has not been studied.

We hypothesized that the investigation of IFN signal transduction could explain the differences in the IFNs' action, as well as the sensitivity of HCC cells to the IFNs. We found that the IFN-sensitive cells express higher IFNAR2, and subsequent phosphorylations of STAT1 and 3 by the IFNs were higher in these cells. Conversely, the resistant cells lack the receptor, and their IFN signaling was faint (Figs. 1, 3 and 4). The experiments on $\mathrm{HuH} 7$ cells, which express low IFNAR2, revealed the occurrence of stronger and persistent induction of pSTAT1 and 3 by IFN- $\beta$ compared to that induced by IFN- $\alpha$. Still in vivo induction of pSTAT3 was more frequently observed in IFN- $\beta$-treated tumors than in IFN- $\alpha$ treated tumors. Therefore, the strong and continual signaling by IFN- $\beta$ in $\mathrm{HuH} 7$ cells may activate the transcription of

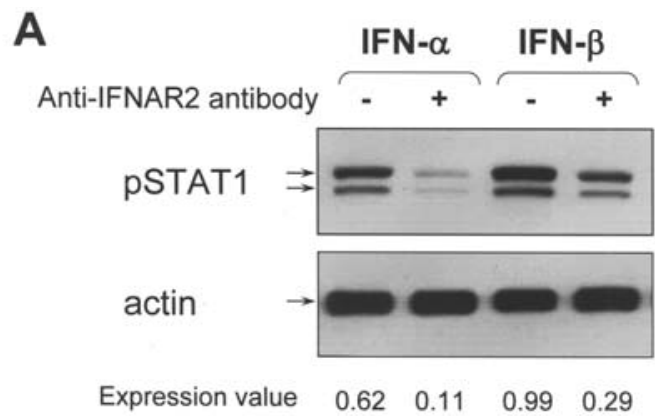

B

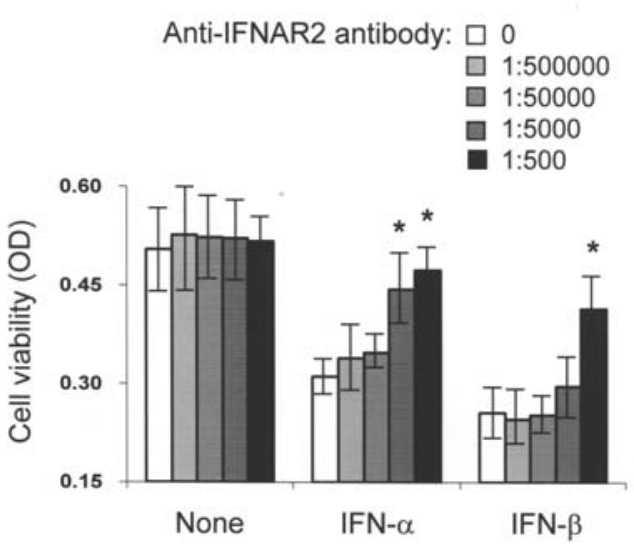

Figure 6. Neutralizing assays with anti-human IFNAR2 antibody on PLC/ $\mathrm{PRF} / 5$ cells. (A) Blockade of IFN signaling by the antibody. The cells were incubated with or without 1:5000 diluted anti-IFNAR2 antibody for $24 \mathrm{~h}$, then they were induced with $2.5 \mathrm{ng} / \mathrm{ml}$ either of IFN- $\alpha$ or IFN- $\beta$. Induction of pSTAT1 was blocked for both IFNs, but less for IFN- $B$, with the antibody. The expression value of each protein band was calculated relative to that of actin. Data are representative of similar results of repeat experiments. (B) The antiproliferative effect of the IFNs $(2.5 \mathrm{ng} / \mathrm{ml})$ was examined in the presence of serial dilutions of anti-IFNAR2 antibody as described in Materials and methods. The antibody significantly reduced the antiproliferative effect of IFNs ( ${ }^{*} \mathrm{p}<0.05$ vs control without the antibody by Dunnett's test). Suppression of the effects of IFN- $\beta$ required more antibody than that of IFN- $\alpha$.

various genes that result in a more potent antitumor effect. Previous studies reported that the IFNs produce variable induction of apoptosis and cell cycle inhibition in cancer cells (20-22).

Because the IFNs' signaling was different, we tried to investigate the binding of the IFNs to the receptors. For this purpose, we performed neutralizing experiments using an antibody binding to the extracellular part of IFNAR2. Our results on an HCC cell line with abundant receptor showed distinct suppression of the IFNs' effect and signal transduction when IFNAR2 is blocked (Fig. 6). This suggested that IFN- $\alpha$ and IFN- $\beta$ interact with IFNAR2 differently, although they share a common receptor. We also performed the neutralizing experiments on $\mathrm{HuH} 7$ cells, however the results were insignificant, perhaps because of less IFNAR2 expression in these cells and/or lower growth-inhibitory effect of the IFNs (data not shown). Differences in binding the IFNs to the IFN receptors were discussed previously; IFNAR2c subunit was distinctive for IFN- $\alpha$ and IFN- $\beta(23,24)$, or binding centers of the IFNs were different on the same IFNAR2 (25). Besides, the results may be related to the higher affinity binding of IFN- $\beta$ with the receptors than that of IFN- $\alpha$ (26). 
Our findings further support these observations and were in agreement with suggestions that IFN- $\alpha$ 's signaling might be transferred mainly through IFNAR2 $(9,10)$, or blocking of IFNAR2 alone appears to be less sufficient for suppression of IFN- $ß$ signal transduction.

From a clinical point of view, the usefulness of IFN- $\alpha$ monotherapy for $\mathrm{HCC}$ has been denied by randomized controlled trail study (27), and the promising combination therapy with subcutaneous IFN- $\alpha$ and intra-arterial $5-\mathrm{FU}$ is less effective for patients with low IFNAR2 expression in tumor (6). Moreover, we found that $35 \%$ of the HCC patients exhibit no or faint expression of IFNAR2 (28). The correlation between clinical response of cancer patients to IFN therapy and in vitro susceptibility of malignant cells to IFN was reported previously (29). Therefore the present and our previous (13) in vitro and in vivo studies suggest that IFN- $\beta$ and/or its combination with anticancer drugs are promising for the treatment of human HCC with a possibility to improve the response rate, especially for patients with less IFNAR2.

In conclusion, our results suggest that the HCC cells that express low IFNAR2 and are resistant to IFN- $\alpha$, might be sensitive to the growth-inhibitory effect of IFN- $\beta$, which is mediated by stronger IFN signal transduction and has different binding to IFNARs compared to IFN- $\alpha$.

\section{Acknowledgments}

This study was supported by a Grant-in-Aid for Scientific Research and for JSPS fellow provided by the Ministry of Education, Culture, Sports, Science and Technology, Japan. B.D. is a postdoctoral fellow supported by Japan Society for the Promotion of Science. The authors thank the Otsuka Pharmaceutical Co. for providing anti-human IFNAR polyclonal antibody.

\section{References}

1. El-Serag HB: Hepatocellular carcinoma: an epidemiologic view. J Clin Gastroenterol 35: S72-S78, 2002.

2. Llovet JM, Burroughs A and Bruix J: Hepatocellular carcinoma. Lancet 362: 1907-1917, 2003.

3. Sakon M, Nagano H, Dono K, Nakamori S, Umeshita K, Yamada A, Kawata S, Imai Y, Iijima S and Monden M: Combined intraarterial 5-fluorouracil and subcutaneous interferon-alpha therapy for advanced hepatocellular carcinoma with tumor thrombi in the major portal branches. Cancer 94: 435-442, 2002.

4. Patt YZ, Hassan MM, Lozano RD, Brown TD, Vauthey JN, Curley SA and Ellis LM: Phase II trial of systemic continuous fluorouracil and subcutaneous recombinant interferon Alfa- $2 b$ for treatment of hepatocellular carcinoma. J Clin Oncol 21: 421-427, 2003.

5. Nagano H, Sakon M, Eguchi H, Kondo M, Yamamoto T, Ota H, Nakamura M, Wada H, Damdinsuren B, Marubashi S, Miyamoto A, Takeda Y, Dono K, Umeshita K, Nakamori S and Monden M: Hepatic resection followed by IFN-alpha and 5-FU for advanced hepatocellular carcinoma with tumor thrombus in the major portal branch. Hepatogastroenterology (In press).

6. Ota H, Nagano H, Sakon M, Eguchi H, Kondo M, Yamamoto T, Nakamura M, Damdinsuren B, Wada H, Marubashi S, Miyamoto A, Dono K, Umeshita K, Nakamori S, Wakasa K and Monden M: Treatment of hepatocellular carcinoma with major portal vein thrombosis by combined therapy with subcutaneous interferon-alpha and intra-arterial 5-fluorouracil; role of type 1 interferon receptor expression. Br J Cancer 93: 557-564, 2005.
7. Obi S, Yoshida H, Toune R, Unuma T, Kanda M, Sato S, Tateishi R, Teratani T, Shiina S and Omata M: Combination therapy of intraarterial 5-fluorouracil and systemic interferonalpha for advanced hepatocellular carcinoma with portal venous invasion. Cancer 106: 1990-1997, 2006.

8. Stark GR, Kerr IM, Williams BR, Silverman RH and Schreiber RD: How cells respond to interferons. Annu Rev Biochem 67: 227-264, 1998.

9. Domanski P, Witte M, Kellum M, Rubinstein M, Hackett R, Pitha $\mathrm{P}$ and Colamonici OR: Cloning and expression of a long form of the beta subunit of the interferon alpha beta receptor that is required for signaling. J Biol Chem 270: 21606-21611, 1995.

10. Kotenko SV, Izotova LS, Mirochnitchenko OV, Lee C and Pestka S: The intracellular domain of interferon-alpha receptor 2c (IFN-alphaR2c) chain is responsible for Stat activation. Proc Natl Acad Sci USA 96: 5007-5012, 1999.

11. Eguchi H, Nagano H, Yamamoto H, Miyamoto A, Kondo M, Dono K, Nakamori S, Umeshita K, Sakon M and Monden M: Augmentation of antitumor activity of 5-fluorouracil by interferon alpha is associated with up-regulation of p27Kip1 in human hepatocellular carcinoma cells. Clin Cancer Res 6: 2881-2890, 2000.

12. Kondo M, Nagano H, Wada H, Damdinsuren B, Yamamoto H, Hiraoka N, Eguchi H, Miyamoto A, Yamamoto T, Ota H, Nakamura M, Marubashi S, Dono K, Umeshita K, Nakamori S, Sakon M and Monden M: Combination of IFN-alpha and 5fluorouracil induces apoptosis through IFN-alpha/beta receptor in human hepatocellular carcinoma cells. Clin Cancer Res 11: 1277-1286, 2005.

13. Damdinsuren B, Nagano H, Sakon M, Kondo M, Yamamoto T, Umeshita K, Dono K, Nakamori S and Monden M: Interferonbeta is more potent than interferon-alpha in inhibition of human hepatocellular carcinoma cell growth when used alone and in combination with anticancer drugs. Ann Surg Oncol 10: 1184-1190, 2003.

14. Novick D, Cohen B and Rubinstein M: The human interferon alpha/beta receptor: characterization and molecular cloning. Cell 77: 391-400, 1994.

15. Damdinsuren B, Nagano H, Kondo M, Natsag J, Hanada H, Nakamura M, Wada H, Kato H, Marubashi S, Miyamoto A, Takeda Y, Umeshita K, Dono K and Monden M: TGF-beta1induced cell growth arrest and partial differentiation is related to the suppression of Id1 in human hepatoma cells. Oncol Rep 15: 401-408, 2006.

16. Yamamoto T, Nagano H, Sakon M, Wada H, Eguchi H, Kondo M, Damdinsuren B, Ota H, Nakamura M, Marubashi S, Miyamoto A, Dono K, Umeshita K, Nakamori S, Yagita H and Monden M: Partial contribution of tumor necrosis factor-related apoptosisinducing ligand (TRAIL)/TRAIL receptor pathway to antitumor effects of interferon-alpha/5-fluorouracil against Hepatocellular Carcinoma. Clin Cancer Res 10: 7884-7895, 2004.

17. Horikoshi T, Fukuzawa K, Hanada N, Ezoe K, Eguchi H, Hamaoka S, Tsujiya $\mathrm{H}$ and Tsukamoto $\mathrm{T}$ : In vitro comparative study of the antitumor effects of human interferon-alpha, beta and gamma on the growth and invasive potential of human melanoma cells. J Dermatol 22: 631-636, 1995.

18. Giandomenico V, Vaccari G, Fiorucci G, Percario Z, Vannuchi S, Matarrese P, Malorni W, Romeo G and Affabris GR: Apoptosis and growth inhibition of squamous carcinoma cells treated with interferon-alpha, IFN-beta and retinoic acid are associated with induction of the cyclin-dependent kinase inhibitor p21. Eur Cytokine Netw 9: 619-631, 1998.

19. Coradini D, Biffi A, Pirronello E and Di Fronzo G: The effect of alpha-, beta- and gamma-interferon on the growth of breast cancer cell lines. Anticancer Res 14: 1779-1784, 1994.

20. Chawla-Sarkar M, Leaman DW and Borden EC: Preferential induction of apoptosis by interferon (IFN)-beta compared with IFN-alpha2: correlation with TRAIL/Apo2L induction in melanoma cell lines. Clin Cancer Res 7: 1821-1831, 2001.

21. Qin XQ, Runkel L, Deck C, De Dios C and Barsoum J: Interferon-beta induces $\mathrm{S}$ phase accumulation selectively in human transformed cells. J Interferon Cytokine Res 17: 355-367, 1997.

22. Sangfelt O and Strander H: Apoptosis and cell growth inhibition as antitumor effector functions of interferons. Med Oncol 18: 314,2001

23. Domanski P, Nadeau OW, Platanias LC, Fish E, Kellum M, Pitha P and Colamonici OR: Differential use of the betaL subunit of the type I interferon (IFN) receptor determines signaling specificity for IFNalpha 2 and IFNbeta. J Biol Chem 273: 3144-3147, 1998. 
24. Platanias LC, Uddin S, Domanski P and Colamonici OR: Differences in interferon alpha and beta signaling. Interferon beta selectively induces the interaction of the alpha and betaL subunits of the type I interferon receptor. J Biol Chem 271: 23630-23633, 1996.

25. Piehler $\mathbf{J}$ and Schreiber G: Mutational and structural analysis of the binding interface between type I interferons and their receptor Ifnar2. J Mol Biol 294: 223-237, 1999.

26. Russell-Harde D, Wagner TC, Perez HD and Croze E: Formation of a uniquely stable type I interferon receptor complex by interferon beta is dependent upon particular interactions between interferon beta and its receptor and independent of tyrosine phosphorylation. Biochem Biophys Res Commun 255: 539-544, 1999.
27. Llovet JM, Sala M, Castells L, Suarez Y, Vilana R, Bianchi L, Ayuso C, Vargas V, Rodes J and Bruix J: Randomized controlled trial of interferon treatment for advanced hepatocellular carcinoma. Hepatology 31: 54-58, 2000.

28. Kondo M, Nagano H, Sakon M, Yamamoto H, Morimoto O, Arai I, Miyamoto A, Eguchi H, Dono K, Nakamori S, Umeshita K, Wakasa K, Ohmoto Y and Monden M: Expression of interferon alpha/beta receptor in human hepatocellular carcinoma. Int $\mathbf{J}$ Oncol 17: 83-88, 2000.

29. Grander D, Oberg K, Lundqvist ML, Janson ET, Eriksson B and Einhorn S: Interferon-induced enhancement of 2',5'-oligoadenylate synthetase in mid-gut carcinoid tumours. Lancet 336: 337-340, 1990. 